\title{
Neurosurgical management of cerebellar cavernous malformations
}

\author{
Jean G. De Oliveira, M.D., Aziz Rassi-Neto, M.D., Ph.D., \\ Fernando A. P. Ferraz, M.D., Ph.D., and Fernando M. Braga, M.D., Ph.D. \\ Division of Neurosurgery, Department of Neurology and Neurosurgery, \\ Federal University of São Paulo_Escola Paulista de Medicina, São Paulo, Brazil
}

\begin{abstract}
Object. The aim of this study was to analyze cerebellar cavernous malformations (CMs) with respect to epidemiological, clinical, radiological, and therapeutic aspects.

Methods. Between 1984 and 2004, 100 patients were surgically treated for intracranial CMs at the Division of Neurosurgery of Federal University of São Paulo. The authors reviewed the records of 10 patients whose lesions were located in the cerebellum.

There were four male and six female patients (ratio 1:1.5) whose ages ranged from 14 to 45 years (mean age 33 years). Clinical presentation was sudden or acute in all cases, and neuroimaging examinations performed in all patients demonstrated signs of bleeding. The mean size of the malformations was $4.6 \mathrm{~cm}$, and in all but one patient the lesions were totally removed without complications. After a mean follow-up period of 70 months, all patients were considered to be in good or excellent clinical condition.

Conclusions. Cerebellar CMs should be analyzed separately from other posterior fossa CMs. These lesions can reach large sizes and cause massive hemorrhages, resulting in acute or sudden presentation. Surgery is a safe and effective option that provides a curative treatment when a complete removal is achieved.
\end{abstract}

\section{KEY WORDS • cavernous malformation • cavernoma • cerebellum • surgical treatment}

A NGIOGRAPHICALLY occult vascular malformations are divided into four types: AVMs, CMs, venous angioma or DVAs, and capillary telangiectasias. Cavernous malformations are hamartomas of the blood vessels and are pathologically defined as thin-walled capillary spaces without intervening brain tissue. ${ }^{33,50}$

The incidence of CMs ranges from 0.4 to $0.9 \%$ of the general population. They constitute 8 to $15 \%$ of all cerebrovascular malformations, ${ }^{13,29,32,39,44,48}$ and they occur in the supratentorial compartment in 63 to $90 \%$ of cases. ${ }^{8,18 \text {, }}$ ${ }^{23,24}$ Posterior fossa CMs represent 7.8 to $35.8 \%$ of all cases and the brainstem is the most common site of involvement in this compartment (9-35\% of all cases). ${ }^{44}$

In large series, cerebellar CMs constitute 1.2 to $11.8 \%$ of all intracranial cases ${ }^{21,47}$ and 9.3 to $52.9 \%$ of infratentorial cases. ${ }^{20,27}$ However, data in the literature about CMs localized in the cerebellum are limited to case reports. Consequently, epidemiological, clinical, neuroimaging,

Abbreviations used in this paper: $\mathrm{AVM}=$ arteriovenous malformation; $\mathrm{CM}=$ cavernous malformation; $\mathrm{CNS}=$ central nervous system; $\mathrm{CPA}=$ cerebellopontine angle; $\mathrm{CT}=$ computed tomography; DVA $=$ developmental venous anomaly; $\mathrm{MR}=$ magnetic resonance. and therapeutic aspects of cerebellar CMs are neglected because these lesions are analyzed together with other infratentorial CMs that have specific features. We present a relatively large series of cerebellar CMs, focusing on the clinical, neuroimaging, and therapeutic aspects of these lesions.

\section{Clinical Material and Methods}

Between 1984 and 2004, 100 patients harboring CMs involving the CNS were surgically treated at the Division of Neurosurgery of Federal University of São Paulo. We excluded all cases that lacked histopathological confirmation, supratentorial cases, and CMs localized primarily in the brainstem with extension to the cerebellum as well as those CMs located at the CPA, tentorium, and posterior fossa cisterns. Ten patients with CMs localized exclusively in the cerebellum were included.

\section{Patient Population}

Patient characteristics are summarized in Table 1. There were four male and six female patients (ratio 1:1.5). The age range of the patients studied was 14 to 45 years, with a mean age of 33 years at presentation. 
TABLE 1

Summary of patients presenting with cerebellar CMs*

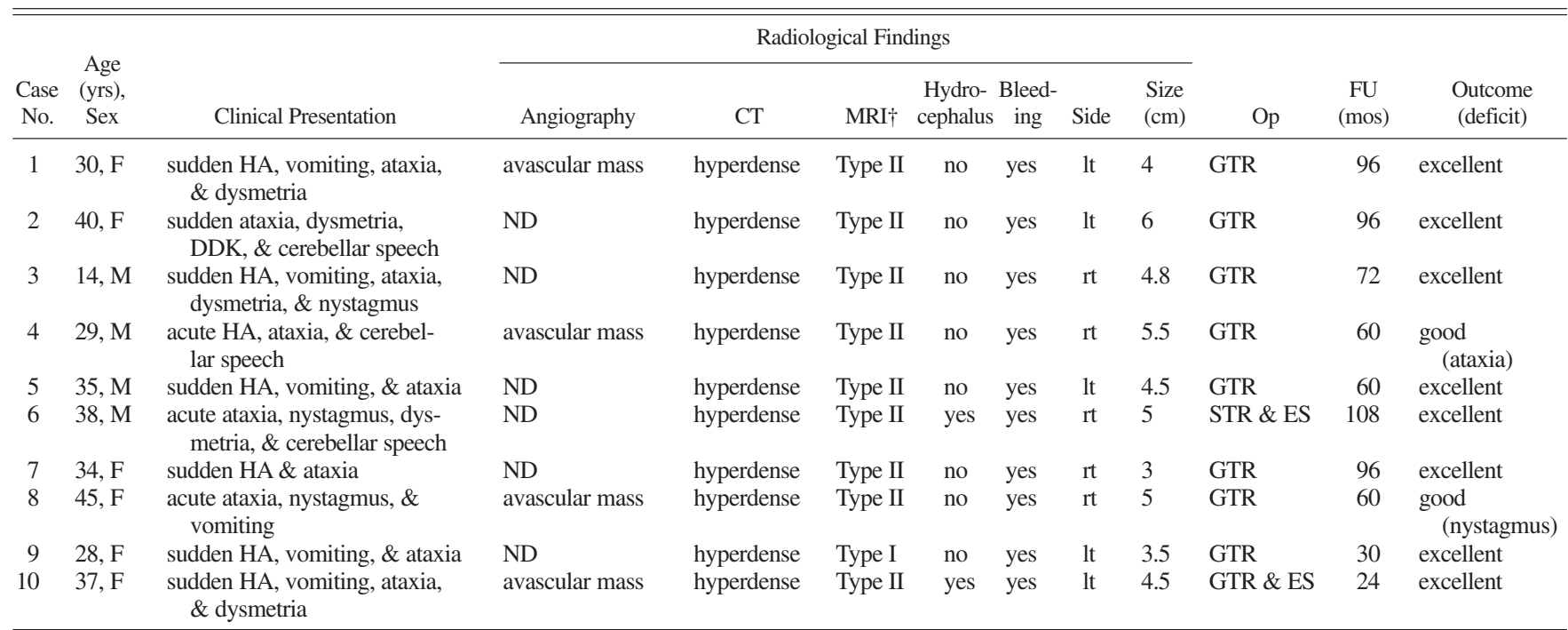

* DDK = dysdiadochokinesia; $\mathrm{ES}=$ external shunt $; \mathrm{FU}=$ follow up; GTR = gross-total removal; HA = headache; ND = not done; STR = subtotal removal.

$\dagger$ Results were analyzed and then classified as one of the four types described by Zabramski, et al.

\section{Results}

The clinical presentation was acute or sudden in all cases and characterized by cerebellar syndrome. Regarding neuroimaging findings, only four patients underwent angiography, and in all four an avascular mass was demonstrated. In each case, CT scans revealed a hyperdensity consistent with hemorrhage. Preoperative MR imaging revealed Type II CMs in all but one patient (who had a Type I lesion) according to the Zabramski, et al., ${ }^{55}$ classification (Table 2). The malformations were equally located on the right and left sides (five patients each). The sizes of the lesions ranged from 3 to $6 \mathrm{~cm}$, with a mean size of $4.6 \mathrm{~cm}$. All 10 patients underwent a standard posterior fossa approach through a craniectomy. Two additional patients with obstructive hydrocephalus underwent placement of an external shunt device immediately before CM removal (Cases 6 and 10). In all but one patient the lesions were totally removed without complications. The patient whose lesion was partially removed (Case 6) was found to be asymptomatic and without increase in the size of the residual lesion on follow-up MR imaging performed 7 years later. No treatment was undertaken because this patient preferred conservative management. After a mean followup duration of 70 months, eight patients were in excellent condition, free of any neurological deficit and symptom free. Two patients had a good outcome with persistent signs and/or symptoms that were no different from their preoperative condition.

\section{Illustrative Cases}

\section{Case 1}

History and Examination. This 30-year-old woman with no significant medical history presented with sudden headache followed by vomiting and was referred to our department. On admission she was alert and the neurological examination disclosed only gait ataxia accompanied by left dysmetria. Because a CT scan revealed a heterogeneous hyperdense lesion on the left cerebellar hemisphere (Fig. 1A), the patient underwent angiography studies, which revealed an avascular mass (Fig. 1B). Admission MR images were also obtained and the results were consistent with CMs and hemorrhage (Fig. 2).

Operation and Postoperative Course. A standard suboccipital approach was performed and a large, hemorrhagic, mulberry-like lesion (Fig. 3A) was encountered. A complete removal was performed without complications and the histological diagnosis confirmed a CM (Fig. 3B). The postoperative period was uneventful and at her 96-month follow-up evaluation the patient presented without neurological deficit. A follow-up MR image confirmed complete removal of the CM (Fig. 4).

\section{Case 2}

History and Examination. This 40-year-old woman presented to the emergency department because she experienced a sudden gait disturbance and speech impairment. On admission she was awake, alert, and oriented. The neurological examination disclosed cerebellar speech, gait ataxia, dysmetria, and dysdiadochokinesia. Admission CT scans revealed a hyperdense lesion on the vermis and left cerebellar hemisphere (Fig. 5). An MR image demonstrated a typical CM Type II lesion (Fig. 6).

Operation and Postoperative Course. The patient was admitted to the neurosurgical department and a standard suboccipital approach was recommended, during which a large, hemorrhagic, mulberry-like lesion (Fig. 7A) was encountered. Complete removal was achieved without complications and the postoperative period was uneventful. Histological examination of the specimen was consistent with a CM (Fig. 7B). At her 96-month follow-up eval- 


\section{Neurosurgical management of cerebellar cavernous malformations}

TABLE 2

Magnetic resonance imaging classification for cavernous malformations*

\begin{tabular}{|c|c|c|}
\hline Lesion Type & MR Signal Characteristics & Pathological Characteristics \\
\hline Type I & $\begin{array}{l}\mathrm{T}_{1} \text {-weighted: hyperintense core } \\
\mathrm{T}_{2} \text {-weighted: hyper- or hypointense core w/ } \\
\quad \text { surrounding hypointense rim }\end{array}$ & $\begin{array}{l}\text { subacute hemorrhage, surrounded by a rim of hemosiderin- } \\
\text { stained macrophages \& gliotic brain }\end{array}$ \\
\hline Type II & $\begin{array}{l}\mathrm{T}_{1} \text {-weighted: reticulated mixed signal core } \\
\mathrm{T}_{2} \text {-weighted: reticulated mixed signal core w/ } \\
\text { surrounding hypointense rim }\end{array}$ & $\begin{array}{l}\text { loculated areas of hemorrhage \& thrombosis of varying } \\
\text { age, surrounded by gliotic, hemosiderin-stained brain; in } \\
\text { large lesions, areas of calcification may be seen }\end{array}$ \\
\hline Type III & $\begin{array}{l}\mathrm{T}_{1} \text {-weighted: iso- or hypointense } \\
\mathrm{T}_{2} \text {-weighted: hypointense } \mathrm{w} / \text { a hypointense rim } \\
\text { that magnifies the size of the lesion } \\
\text { gradient-echo: hypointense w/ greater magnification } \\
\text { than } \mathrm{T}_{2}\end{array}$ & $\begin{array}{l}\text { chronic resolved hemorrhage, w/ hemosiderin staining } \\
\text { w/in \& around the lesion. }\end{array}$ \\
\hline Type IV & $\begin{array}{l}\mathrm{T}_{1} \text {-weighted: poorly seen or not visualized at all } \\
\mathrm{T}_{2} \text {-weighted: poorly seen or not visualized at all } \\
\text { gradient-echo: punctate hypointense lesions }\end{array}$ & $\begin{array}{l}\text { two lesions in the category have been pathologically docu- } \\
\text { mented to be telangiectasias }\end{array}$ \\
\hline
\end{tabular}

* Reprinted from Zabramski, et al.

uation the patient had completely recovered from her neurological deficit, and MR images confirmed complete removal of the lesion (Fig. 8).

\section{Discussion}

Cavernous malformations are encountered in 0.4 to $0.9 \%$ of the general population and constitute between 8 and $15 \%$ of all CNS vascular malformations. ${ }^{13,29,32,38,44,48}$ Cavernous malformations are more commonly located in the supratentorial compartment (in as many as $90 \%$ of cases). ${ }^{3,5,9,13,18,23,29,38,41,43,48,51,53}$ Most of the posterior fossa CMs are located in the brainstem, ${ }^{24}$ and therefore cerebellar CMs are rare lesions.

\section{Age and Sex of the Patients}

The majority of CMs present between the 3rd and 5th decades of life. ${ }^{24}$ The median age of patients at presentation in clinical series of intracranial CMs ranges from 32.2 to 37.6 years. ${ }^{1,5,9,13,29,31,38,43,48,49}$ The mean age of our patients, 33 years, is no different compared with the age of patients who have CMs in other locations.

Some authors have observed a higher incidence of CMs in the CNS of male patients, ${ }^{18,41,55}$ and others have found a higher incidence in females. ${ }^{11,39,51,52}$ In most series, however, an equal distribution between the sexes ${ }^{13,24,26,31,40,43,48,53}$ has been reported, and this was also the case in ours. Some authors have suggested a higher propensity for bleeding episodes in female patients, ${ }^{16,48}$ often during pregnancy. ${ }^{45}$ There has also been a report of sudden death in a pregnant patient, in whom a cerebellar CM was diagnosed at autopsy. ${ }^{19}$

\section{Clinical Presentation}

In general, CMs are associated with a wide range of clinical syndromes ${ }^{47}$ although they can be found incidentally in up to $21 \%$ of all intracranial cases. ${ }^{24}$ The most common presentation of CMs located in the supratentorial compartment is seizures.$^{36}$ Nevertheless, there is an unusual description of posterior fossa CMs presenting with seizures. ${ }^{6}$

Because of their anatomical proportions, even small lesions located in the brainstem or cranial nerves in the posterior fossa can cause symptoms. ${ }^{8}$ The exception is extraaxial lesions arising from the CPA; these can reach a large size and cause symptoms by compressing the cerebellum, brainstem, and cranial nerves. ${ }^{14}$

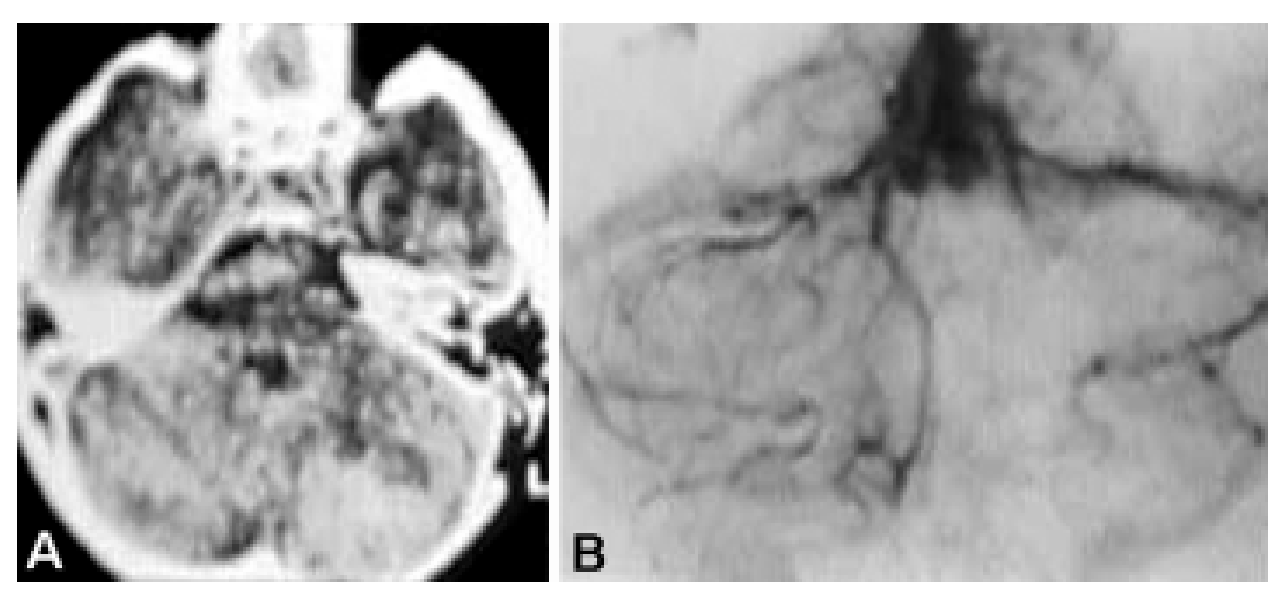

FIG. 1. Case 1. A: Preoperative CT scan revealing a hyperdense lesion on the left cerebellar hemisphere. B: Angiography study revealing an avascular mass on the left cerebellar hemisphere. 


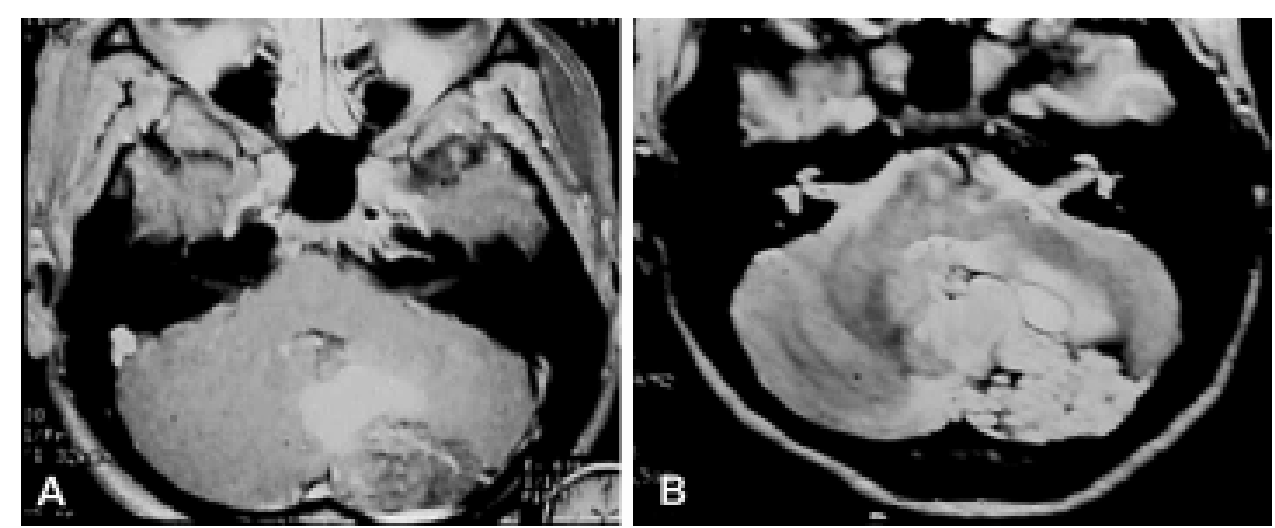

Fig. 2. Case 1. Axial $\mathrm{T}_{1^{-}}$(A) and $\mathrm{T}_{2}$-weighted (B) MR images consistent with a Type II CM lesion.

Patients harboring infratentorial CMs tend to present with progressive focal neurological deficits. ${ }^{48}$ Among our 10 patients, however, eight had a sudden and two an acute presentation, with signs and symptoms of cerebellar syndrome. An acute or sudden presentation caused by hemorrhage is found in approximately $33 \%$ of intracranial CMs. ${ }^{8}$

\section{Neuroimaging Findings}

Cavernous malformations are angiographically occult vascular malformations. Nevertheless, when they are large they may appear as an avascular mass on angiography studies. ${ }^{46,51}$ We performed angiography in four of our 10 patients, and an avascular mass was present in all of them.

Findings on CT scans are nonspecific; CMs generally appear as a heterogeneous hyperdense lesion without enhancement. This hyperdensity corresponds to either hemorrhage or calcification. ${ }^{23,46}$ Perilesional hypodensity can be found, and it may represent edema, hemosiderin, or even atrophy. ${ }^{23,52}$ The CMs can be present as a cystic lesion that is isodense or hypodense on CT scans, with or without a wall nodule, and consequently, differentiation from posterior fossa gliomas is very difficult based on CT

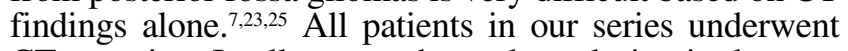
CT scanning. In all cases, a hyperdense lesion in the posterior fossa was present.

Magnetic resonance imaging has dramatically changed our ability to diagnose CMs. ${ }^{8} 46$ Based on MR imaging findings, CMs were classified in four types by Zabramski, et al. ${ }^{55}$ Whereas $93 \%$ of the Type I and II lesions were symptomatic, only $33 \%$ of the Type III and IV lesions caused corresponding symptoms. Among our patients, nine had a Type II lesion and in only one case the MR imaging findings were consistent with Type I.

An association between CM and DVA has a variable incidence. ${ }^{5,44}$ This association shows a preference for the posterior fossa location and female patients, and this kind of lesion tends to bleed and rebleed more frequently than isolated CMs. ${ }^{1}$ Nevertheless, there was no associated DVA in any patient in our series.

The mean size of CMs reported in several large series was between 15 and $19 \mathrm{~mm}$ in diameter.,2,29,48 According to some authors, the larger the lesion the higher the chance
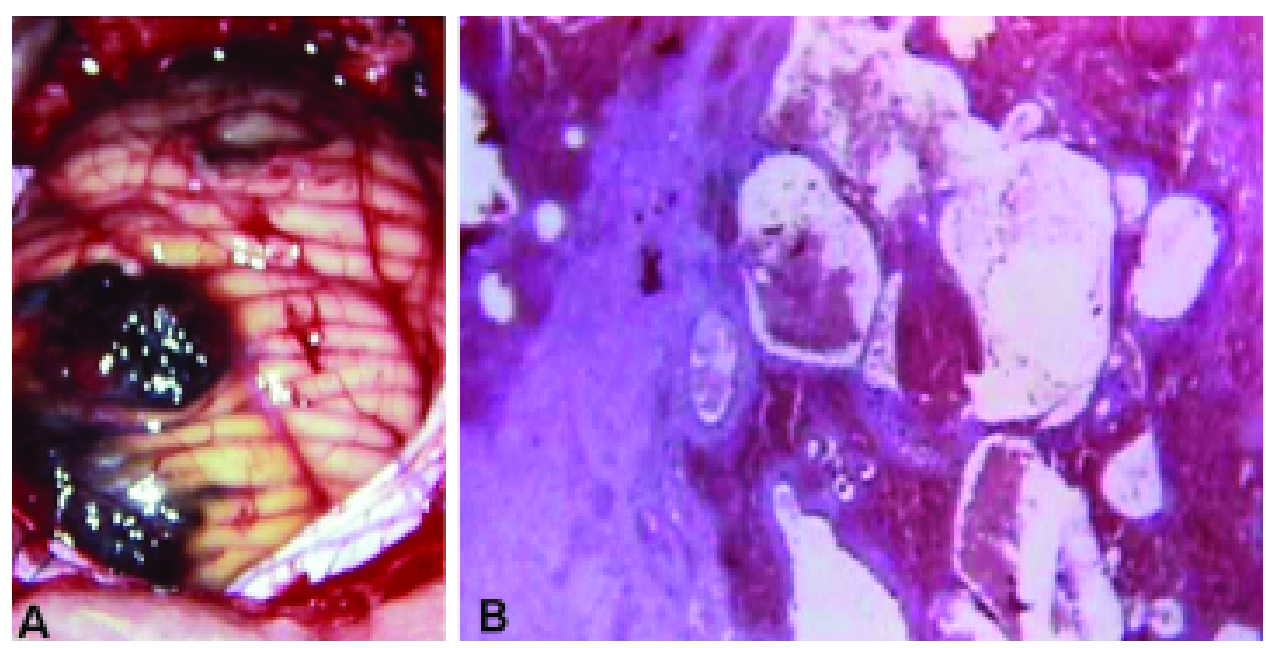

Fig. 3. Case 1. A: Intraoperative photograph obtained after opening the dura mater through a suboccipital approach, showing a hemorrhagic, mulberry-like lesion. B: Photomicrograph of a histological specimen of the resected CM. $\mathrm{H}$ $\&$ E, original magnification $\times 200$. 

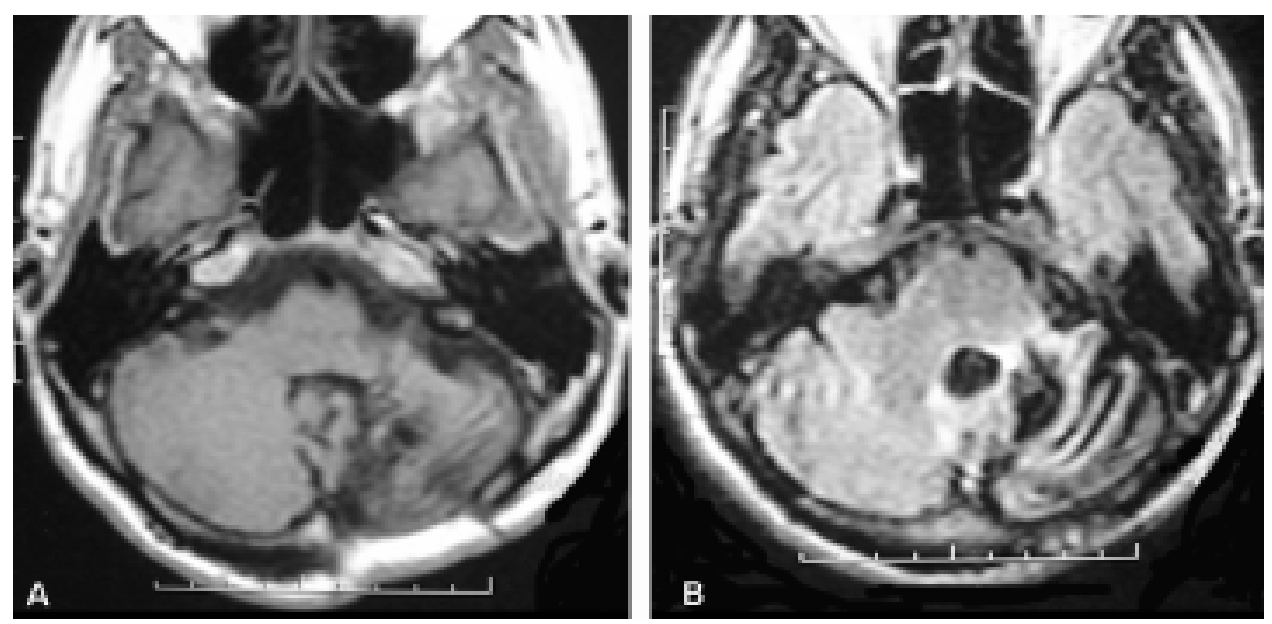

Fig. 4. Case 1. Postoperative $T_{1}-(A)$ and $T_{2}$-weighted (B) MR images demonstrating complete removal of the $C M$.

that symptoms will appear. ${ }^{24}$ Bertalanffy, et al. ${ }^{8}$ reported that most symptomatic patients present with lesions larger than $1 \mathrm{~cm}$. Cavernous malformations arising from the posterior fossa may be smaller at the time of diagnosis. ${ }^{8,14} \mathrm{In}$ terestingly, all patients in our series presented with large lesions (mean $4.6 \mathrm{~cm}$ ).

\section{Treatment Options}

Just as in aneurysms and AVMs, the decision about the best treatment for CMs must compare the risk of bleeding with the risk inherent to the therapeutic option. Because the natural history of CMs is not completely understood, the rates of hemorrhage as well as the rates of morbidity and mortality from the lesion itself vary greatly in the literature. ${ }^{8}$ Consequently, in the management of CMs the surgeon must consider each patient individually.

The annual risk of bleeding for CMs is reported to be $2.2 \%$ per patient. For those who have suffered previous bleeding, the annual risk increases to $4.3 \%$ per patient. ${ }^{16} \mathrm{In}$ those harboring posterior fossa CMs and those who have experienced a previous hemorrhage it is 6.75 and 7.78 times more likely, respectively, that they will present with neurological sequelae. ${ }^{39,45}$ Cantu, et al., ${ }^{10}$ reported that the risk of intracerebral hemorrhage was only $1.22 \%$ per patient per year in lobar CMs and 2.33, 2.39, and 2.82\% per patient per year for brainstem, cerebellum, and deep hemispheric CMs, respectively.

The current literature about CM management defines three therapeutic options: conservative (observation), radiosurgery, and surgery. ${ }^{28,34,37}$ All patients included in our series underwent surgical treatment.

Conservative Management. Overall, conservative management is recommended for patients harboring asymptomatic lesions without bleeding, especially if deeply located, in eloquent areas, or in patients with multiple lesions. ${ }^{33,34}$ Patients who underwent conservative treatment
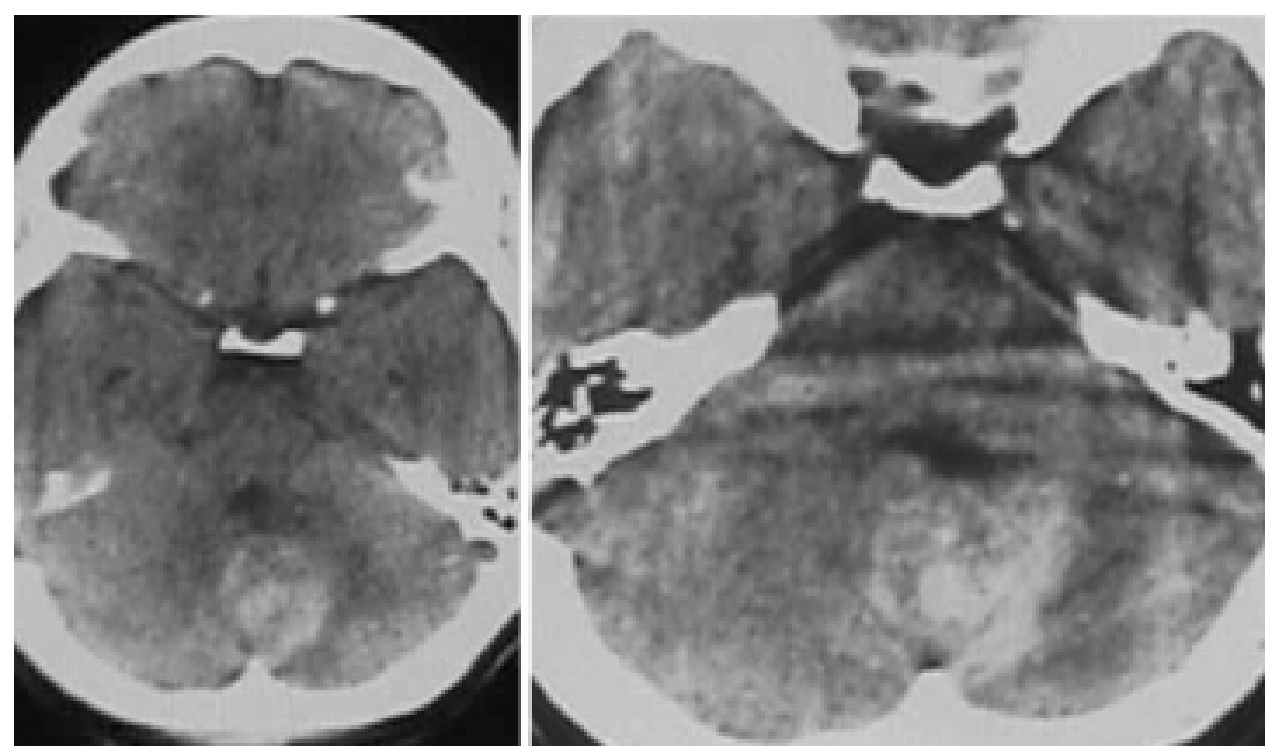

Fig. 5. Case 2. Admission CT scans revealing a hyperdense lesion on the vermis and the left cerebellar hemisphere. 

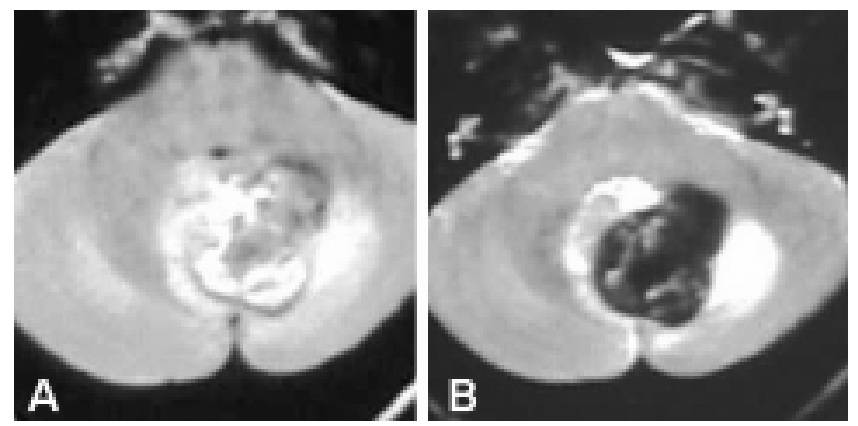

Fig. 6. Case 2. Preoperative $T_{1^{-}}(\mathrm{A})$ and $\mathrm{T}_{2}$-weighted (B) $\mathrm{MR}$ images demonstrating a Type II CM in the left cerebellar hemisphere.

were prospectively analyzed and, after a mean of 34 months of clinical follow up, the annual rate of rebleeding was $2.6 \% .{ }^{31}$ Some authors described a silent hemorrhage of CM and defined the annual rate of asymptomatic bleeding as $13 \%$ per patient and $2 \%$ per lesion. In addition, due to the dynamic behavior of CMs, periodic follow-up MR images are recommended..$^{55}$

Radiosurgery. There is no evidence that radiosurgery is an effective treatment for CMs. This is particularly true because there is no reliable neuroimaging modality that can be used to document total lesion occlusion. ${ }^{28}$ Consequently, the only way to evaluate the effectiveness of radiosurgery in CMs is to analyze the reduction in the bleeding rate. In high-flow vascular malformations such as AVMs, the gap between radiosurgery and lesion obliteration is approximately 2 years. ${ }^{31}$ Nevertheless, the role of radiosurgery for low-flow vascular malformations like CMs remains controversial. ${ }^{8}$

Although some authors report a reduction in the rate of hemorrhage in patients whose CMs are treated with radiosurgery, ${ }^{21,30}$ others not only failed to confirm such a reduction but also showed a high incidence of complications induced by radiation. ${ }^{4,26,42}$ Gewirtz, et al., ${ }^{17}$ found no evidence of vascular obliteration in histopathological samples of CMs that were previously treated with radiation (either conventional radiotherapy or stereotactic radiosurgery), af- ter a mean follow-up period of 3.5 years. There is a report of a cerebellar CM treated with radiosurgery in which the lesion showed reduction without hemorrhage after a mean follow-up duration of 34 months. ${ }^{28}$ The lack of evidence for the effectiveness of radiosurgery for intracranial CMs, along with the risk of a higher rate of radiation-induced complications, justifies prospective randomized studies on this subject. ${ }^{26,35,42}$

Surgical Treatment. Cerebellar hemorrhage from CMs has a wide range of clinical presentations, from minimal symptoms to sudden death caused by massive hemorrhage. ${ }^{12}$ Thus, each patient must be analyzed individually. Patients with symptomatic CMs, with sudden or progressive presentation (with or without radiological evidence of bleeding), and those with recurrent hemorrhage should be considered for surgical treatment. ${ }^{16,29,31}$ Porter and coworkers $^{43}$ showed that after a hemorrhage from a CM treated conservatively, only $37 \%$ of patients experienced complete recovery and $27 \%$ did not improve at all. Consequently, some authors recommend surgical treatment even for asymptomatic CMs, especially if there is evidence of growth on neuroimages. ${ }^{16}$

Surgical management of posterior fossa CMs depends on a wide number of factors such as the patient's clinical condition, age, lesion location, hemorrhage size, presence of mass effect and hydrocephalus, and the morbidity inherent to a surgical approach. ${ }^{8}$ Lesions located in highly eloquent areas such the brainstem, the CPA, and the cranial nerves in the posterior fossa usually present with higher morbidity and mortality rates compared with cerebellar CMs, not only as the consequence of bleeding but also because these lesions frequently require a complex surgical approach. ${ }^{8,14}$ Among our 10 patients, all underwent a standard suboccipital approach and experienced no complications. Consequently, we recommend it as a safe and effective way to manage cerebellar CMs.

Although the eloquence of the cerebellum cannot be compared with the brainstem, cerebellar CMs can reach giant size ${ }^{22}$ or even cause massive hemorrhage. ${ }^{12}$ This may not be well tolerated in the restricted posterior fossa space, causing brainstem compression ${ }^{54}$ or hydrocephalus. ${ }^{15}$ Among our 10 patients, all presented with large lesions in which there was considerable hemorrhage, which caused
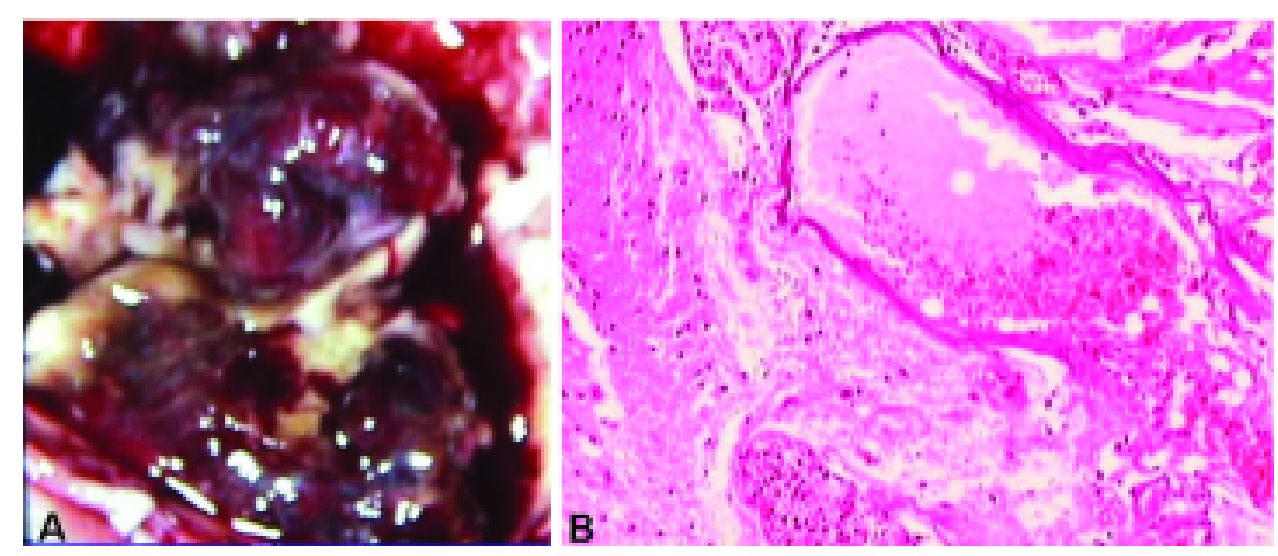

Fig. 7. Case 2. A: Intraoperative photograph obtained after opening the dura via a suboccipital approach, showing a large, hemorrhagic, mulberry-like lesion. B: Photomicrograph of a histological specimen of the resected CM. H \& E, original magnification $\times 100$. 


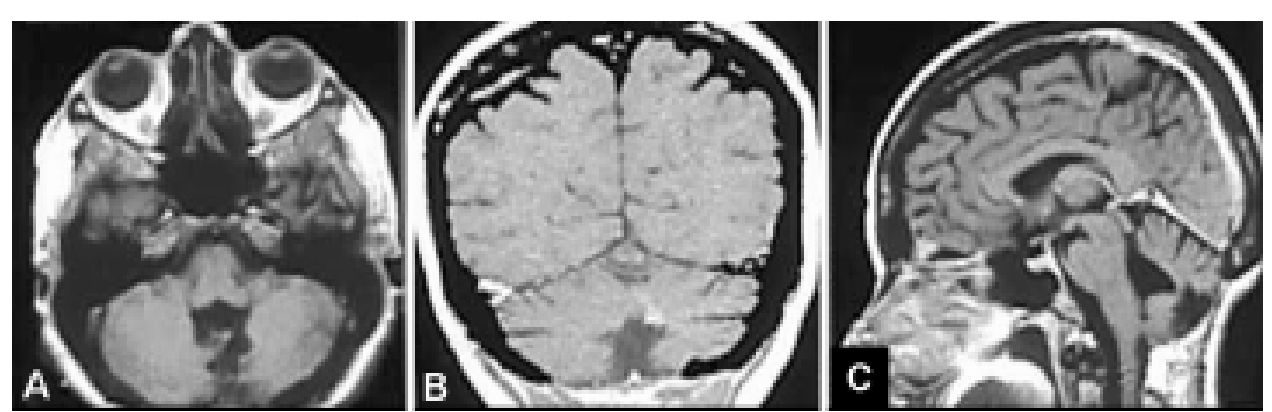

Fig. 8. Case 2. Postoperative axial (A), coronal (B), and sagittal (C) MR images demonstrating complete removal of the $\mathrm{CM}$.

acute or sudden presentation and were responsible for hydrocephalus in two cases. Based on this kind of presentation, some authors recommend surgical treatment for cerebellar CMs, even in patients with asymptomatic lesions, because a hemorrhagic event in a lesion in this location can prove fatal. ${ }^{15,54}$

Pozzati and colleagues ${ }^{45}$ reported on 18 patients among 145 whose CMs exhibited aggressive biological behavior characterized by recurrent overt bleeding, growth, or de novo appearance. Consequently, total resection must be emphasized because residual lesions may grow and cause bleeding. ${ }^{14}$ In our series, one patient underwent partial removal (Case 6). This patient remains asymptomatic 108 months after resection, and MR imaging studies showed the absence of bleeding and no increase in the size of the lesion.

\section{Conclusions}

Cerebellar CMs present separate characteristics from other CMs located in the posterior fossa. We investigated a relatively large series of purely cerebellar CMs and found no difference with respect to demographic aspects (age and sex) when compared with patients who had CMs in other locations. All of our patients had an acute or sudden clinical presentation. Probably such a presentation was the consequence of the unusually large size of these lesions, which ranged from 3 to $6 \mathrm{~cm}$ (mean size $4.6 \mathrm{~cm}$ ). Surgical treatment of cerebellar CMs is a safe and effective option. No complication related to surgery occurred in our series, and complete removal was accomplished in nine of 10 cases.

\section{References}

1. Abdulrauf SI, Kaynar MY, Awad IA: A comparison of the clinical profile of cavernous malformations with and without associated venous malformations. Neurosurgery 44:41-47, 1999

2. Abdulrauf SI, Malik GM, Awad IA: Spontaneous angiographic obliteration of cerebral arteriovenous malformations. Neurosurgery 44:280-287, 1999

3. Aiba T, Tanaka R, Koike T, Kameyama S, Takeda N, Komata T: Natural history of intracranial cavernous malformations. J Neurosurg 83:56-59, 1995

4. Amin-Hanjani S, Ogilvy CS, Candia GJ, Lyons S, Chapman $\mathrm{PH}$ : Stereotactic radiosurgery for cavernous malformations: Kjellberg's experience with proton beam therapy in 98 cases at the Harvard Cyclotron. Neurosurgery 42:1229-1238, 1998

5. Amin-Hanjani S, Ogilvy CS, Ojemann RG, Crowell RM: Risks of surgical management for cavernous malformations of the nervous system. Neurosurgery 42:1220-1228, 1998

6. Awad IA, Robinson JR: Cavernous malformations and epilepsy, in Awad IA, Barrow DL (eds): Cavernous Malformations. Park Ridge, Illinois: AANS, 1993, pp 9-63

7. Bellotti C, Medina M, Oliveri G, Barrale S, Ettorre F: Cystic cavernous angiomas of the posterior fossa. Report of three cases. J Neurosurg 63:797-799, 1985

8. Bertalanffy H, Benes L, Miyazawa T, Alberti O, Siegel AM, Sure U: Cerebral cavernomas in the adult. Review of the literature and analysis of 72 surgically treated patients. Neurosurg Rev 25:1-55, 2002

9. Bertalanffy H, Kuhn G, Scheremet R, Seeger W: Indications for surgery and prognosis in patients with cerebral cavernous angiomas. Neurol Med Chir 32:659-666, 1992

10. Cantu C, Murillo-Bonilla L, Arauz A, Higuera J, Padilla J, Barinagarrementeria F: Predictive factors for intracerebral hemorrhage in patients with cavernous angiomas. Neurol Res 27: 314-318, 2005

11. Clatterbuck RE, Moriarity JL, Elmaci I, Lee RR, Breiter SN, Rigamonti D: Dynamic nature of cavernous malformations: a prospective magnetic resonance imaging study with volumetric analysis. J Neurosurg 93:981-986, 2000

12. de Tribolet N, Kaech D, Perentes E: Cerebellar haematoma due to a cavernous angioma in a child. Acta Neurochir (Wien) 60: 37-43, 1982

13. Del Curling O Jr, Kelly DL Jr, Elster AD, Craven TE: An analysis of the natural history of cavernous angiomas. J Neurosurg 75:702-708, 1991

14. Deshmukh VR, Albuquerque FC, Zabramski JM, Spetzler RF: Surgical management of cavernous malformations involving the cranial nerves. Neurosurgery 53:352-357, 2003

15. Di Rocco C, Iannelli A, Tamburrini G: Cavernomas of the central nervous system in children. A report of 22 cases. Acta Neurochir (Wien) 138:1267-1274, 1996

16. Dorsch NWC, McMahon JHA: Intracranial cavernous malformations-natural history and management. Crit Rev Neurosurg 8: $154-168,1998$

17. Gewirtz RJ, Steinberg GK, Crowley R, Levy RP: Pathological changes in surgically resected angiographically occult vascular malformations after radiation. Neurosurgery 42:738-743, 1998

18. Giombini S, Morello G: Cavernous angiomas of the brain. Account of fourteen personal cases and review of the literature. Acta Neurochir (Wien) 40:61-82, 1978

19. Gronsky L, Loyka S: [Cavernous angioma of the cerebellum as cause of sudden death during pregnancy.] Cesk Gynekol 21: 351-352, 1956 (Czech)

20. Hahn M, Aschoff A, Kunze S: 667 histologically verified cavernomas of the CNS (37 personal cases). Review of localisation, symptoms and signs, diagnosis, and results of operative treatment. Adv Neurosurg 19:122-126, 1999

21. Hasegawa T, McInerney J, Kondziolka D, Lee JY, Flickinger 
JC, Lunsford LD: Long-term results after stereotactic radiosurgery for patients with cavernous malformations. Neurosurgery 50:1190-1198, 2002

22. Hayashi T, Fukui M, Shyojima K, Utsunomiya H, Kawasaki K: Giant cerebellar hemangioma in an infant. Childs Nerv Syst 1: 230-233, 1985

23. Houtteville JP: The surgery of cavernomas both supra-tentorial and infra-tentorial. Adv Tech Stand Neurosurg 22:185-259, 1995

24. Hsu FPK, Rigamonti D, Huhn SL: Epidemiology of cavernous malformations, in Awad IA, Barrow DL (eds): Cavernous Malformations. Park Ridge, Illinois: AANS, 1993, pp 13-23

25. Kadota O, Sakaki S, Kumon Y, Ohta S, Kohno K: Large cystic cavernous angioma of the cerebellum-case report. Neurol Med Chir 34:768-772, 1994

26. Karlsson B, Kihlstrom L, Lindquist C, Ericson K, Steiner L: Radiosurgery for cavernous malformations. J Neurosurg 88: 293-297, 1998

27. Kattapong VJ, Hart BL, Davis L: Familial cerebral cavernous angiomas: clinical and radiologic studies. Neurology 45: 492-497, 1995

28. Kim DG, Choe WJ, Paek SH, Chung HT, Kim IH, Han DH: Radiosurgery of intracranial cavernous malformations. Acta Neurochir (Wien) 144:869-878, 2002

29. Kim DS, Park YG, Choi JU, Chung SS, Lee KC: An analysis of the natural history of cavernous malformations. Surg Neurol 48:9-18, 1997

30. Kondziolka D, Lunsford LD, Flickinger JC, Kestle JR: Reduction of hemorrhage risk after stereotactic radiosurgery for cavernous malformations. J Neurosurg 83:825-831, 1995

31. Kondziolka D, Lunsford LD, Kestle JR: The natural history of cerebral cavernous malformations. J Neurosurg 83:820-824, 1995

32. Labauge P, Laberge S, Brunereau L: Clinical and genetic study of 57 French familial cavernomas pedigrees. Neurology (Suppl 4) 50:441, 1998

33. Maraire JN, Awad IA: Intracranial cavernous malformations: lesion behavior and management strategies. Neurosurgery 37: 591-605, 1995

34. Michelson WJ: Conservative management, in Awad IA, Barrow DL (eds): Cavernous Malformations. Park Ridge, Illinois: AANS, 1993, pp 81-85

35. Mitchell P, Hodgson TJ, Seaman S, Kemeny AA, Forster DM: Stereotactic radiosurgery and the risk of haemorrhage from cavernous malformations. Brit J Neurosurg 14:96-100, 2000

36. Moran NF, Fish DR, Kitchen N, Shorvon S, Kendall BE, Stevens JM: Supratentorial cavernous haemangiomas and epilepsy: a review of the literature and case series. J Neurol Neurosurg Psychiatry 66:561-568, 1999

37. Morcos JJ, Heros RC, Frank DE: Microsurgical treatment of infratentorial malformations. Neurosurg Clin Am 10:441-474, 1999

38. Moriarity JL, Clatterbuck RE, Rigamonti D: The natural history of cavernous malformations. Neurosurg Clin Am 10:411-417, 1999

39. Moriarity JL, Wetzel M, Clatterbuck RE, Javedan S, Sheppard JM, Hoenig-Rigamonti K, et al: The natural history of cavernous malformations: a prospective study of 68 patients. Neurosurgery 44:1166-1173, 1999

40. Murillo-Bonilla LM, Cantu-Brito C, Arauz-Gongora A, Higuera-Calleja J, Padilla-Rubio J, Barinagarrementeria-Aldatz
F: Angiomas cavernosos. Observaciones clinicas y pronostico de 133 pacientes. Rev Invest Clin 55:387-393, 2003

41. Otten P, Pizzolato GP, Rilliet B, Berney J: A propos de 131 cas d'angiomes caverneux (cavernomes) du s.n.c, reperes par l'analyse retrospective de 24,535 autopsies. Neurochirurgie 35: 82-83, 128-131, 1989

42. Pollock BE, Garces YI, Stafford SL, Foote RL, Schomberg PJ, Link MJ: Stereotactic radiosurgery for cavernous malformations. J Neurosurg 93:987-991, 2000

43. Porter PJ, Willinsky RA, Harper W, Wallace MC: Cerebral cavernous malformations: natural history and prognosis after clinical deterioration with or without hemorrhage. J Neurosurg 87: 190-197, 1997

44. Porter RW, Detwiler PW, Spetzler RF, Lawton MT, Baskin JJ, Derksen PT, et al: Cavernous malformations of the brainstem: experience with 100 patients. J Neurosurg 90:50-58, 1999

45. Pozzati E, Acciarri N, Tognetti F, Marliani F, Giangaspero F: Growth, subsequent bleeding, and de novo appearance of cerebral cavernous angiomas. Neurosurgery 38:662-670, 1996

46. Rabinov JD: Diagnostic imaging of angiographically occult vascular malformations. Neurosurg Clin N Am 10:419-432, 1999

47. Robinson JR, Awad IA: Clinical spectrum and natural course, in Awad IA, Barrow DL (eds): Cavernous Malformations. Park Ridge, Illinois: AANS, 1993, pp 25-36

48. Robinson JR, Awad IA, Little JR: Natural history of the cavernous angioma. J Neurosurg 75:709-714, 1991

49. Robinson JR Jr, Awad IA, Magdinec M, Paranandi L: Factors predisposing to clinical disability in patients with cavernous malformations of the brain. Neurosurgery 32:730-736, 1993

50. Russell DS, Rubinstein LJ: Tumours and hamartomas of the blood-vessels, in Pathology of Tumours of the Nervous System. London: Edward Arnold Ltd, 1959, pp 72-92

51. Simard JM, Garcia-Bengochea F, Ballinger WE Jr, Mickle JP, Quisling RG: Cavernous angioma: a review of 126 collected and 12 new clinical cases. Neurosurgery 18:162-172, 1986

52. Vaquero J, Salazar J, Martinez R, Martinez P, Bravo G: Cavernomas of the central nervous system: clinical syndromes, CT scan diagnosis, and prognosis after surgical treatment in 25 cases. Acta Neurochir (Wien) 85:29-33, 1987

53. Voigt K, Yaşargil MG: Cerebral cavernous haemangiomas or cavernomas. Incidence, pathology, localization, diagnosis, clinical features and treatment. Review of the literature and report of an unusual case. Neurochirurgia (Stuttg) 19:59-68, 1976

54. Yoshimoto Y, Wakai S, Ochiai C, Okuhata S, Nagai M: Early fatal rebleeding from a cerebellar cavernous malformation-case report. Neurol Med Chir 37:343-345, 1997

55. Zabramski JM, Wascher TM, Spetzler RF, Johnson B, Golfinos J, Drayer BP, et al: The natural history of familial cavernous malformations: results of an ongoing study. J Neurosurg 80: 422-432, 1994

Manuscript received April 13, 2006.

Accepted in final form May 30, 2006.

During this work, Dr. de Oliveira was a grant recipient from Coordenação de Aperfeiçoamento de Pessoal de Nível Superior (CAPES) (www.capes.gov.br).

Address reprint requests to: Jean Gonçalves de Oliveira, M.D., Rua Sena Madureira, 1123 Apto. 61, 04021-051 São Paulo, Brasil. email: jeangol@uol.com.br. 